\title{
Left Fallopian Tube
}

National Cancer Institute

\section{Source}

National Cancer Institute. Left Fallopian Tube. NCI Thesaurus. Code C32959.

The fallopian tube that extends from the uterus to the ovary in the left side of the pelvic cavity. 